\title{
Shaft of humerus fracture managed by anteromedial plating through anterolateral approach.
}

1. MBBS, MRCS, FCPS

Assistant Professor Orthopedic Surgery

United Medical \& Dental College.

2. MBBS, FCPS

Assistant Professor Orthopedic

Surgery

Shaheed Nuhatarma Benazir Bhutto

Medical College Liyari Karachi.

3. MBBS, FCPS

Assistant Professor Orthopedic

Surgery

Khairpur Medical College.

4. MBBS, MRCS, FCPS

Consultant Orthopedic Surgeon Awadh General Hospital Karachi.

5. MBBS, MS (Orthopedic Surgery) Consultant Orthopedic Surgeon

Sindh Government Qatar Hospital Karachi.

6. MBBS, FCPS

Consultant Orthopedic Surgeon

KVSS Site Hospital Karachi.

\section{Correspondence Address:}

Dr. Masroor Ahmed

Department of Orthopedic Surgery United Medical \& Dental College.

mbsurgeon14@gmail.com

Article received on:

09/05/2020

Accepted for publication:

$31 / 10 / 2020$

\section{INTRODUCTION}

The shaft of humerus fractures in adults accounts for about $3 \%$ of such injuries. ${ }^{1}$ The majority of the fractures involve the middle third of the humerus shaft, constituting about $60 \%$ of the total. ${ }^{2}$ The main aim of treating the shaft of humerus fractures is to achieve acceptable alignment, the union of fracture, and bring the patient back to the optimum functioning level of function. ${ }^{3}$ Conservative measures can manage these types of injuries but are associated with joints stiffness due to prolonged immobilization, nonunion, or pseudo-arthrosis at the fracture site. ${ }^{4}$

Surgical options for treating shaft of humerus fractures include intramedullary nailing or plates and screws after open reduction and internal fixation. ${ }^{1,5}$ Both options have their pros and cons, intramedullary nailing being the biologic fixation. Even without exposing the fracture site, it may cause rotator cuff injuries, tendinopathies and may lead to delayed union or non-union. . $^{6,7}$ Plate and screws are the rigid construct, but exposing the shaft of humerus and stripping of soft tissues and periosteum may lead to infection, loss of vascularity to bone leading to nonunion even are associated with iatrogenic nerve injury despite all these are associated with good clinical outcome. ${ }^{8}$

Usually, the plate and screw construct is applied on the anterolateral or posterior surfaces of humerus $^{9}$, but when placed on these two surfaces, the radial nerve injury rate is around $5.1 \% .^{10}$ Similarly, a study conducted by Akan et $\mathrm{al}^{11}$ showed that applying an anteromedial plate was associated with very low chances of 
iatrogenic injury of radial nerve that was prevalent with other application sites, i.e., posterior surface and the anterolateral surface of the humerus.

The purpose of this research was to assess the use of anteromedial plating in the shaft of humerus fractures concerning the union of fracture and to assess the frequency of complications associated with this approach.

\section{MATERIAL \& METHODS}

This cross sectional study was carried out at United Medical and Dental College, Shaheed Muhatarma Benazir Bhutto Medical College Lyari and Khairpur Medical College from 15 January 2016 to 15 January 2019. Ethical approval was obtained from the ethical review committee (UMDC/Ethic/2016/1/1/245) before the study. Non probability consecutive sampling technique was used for sample collection. All the patients aged 18 years or over presenting with the shaft of humerus fracture were included in the study. Patients with open fractures, pathological fracture, polytrauma patients, or patients with intraarticular fracture elbow joint or proximal humerus were excluded from the study. The patient was assessed clinically and radiologically and informed written consent was obtained before inclusion into the study. The x-rays, i.e., AP and lateral of the affected humerus with joint above and joint below, were obtained to assess the fracture pattern. All the fractures were classified according to AO classification. The anterolateral approach was used to expose the fracture, and the plate was applied on the anteromedial surface of the humerus. The patient was evaluated clinically and radiologically after every two weeks, and the union was assessed at six weeks and onwards. Rodriguez Merchan criteria assessed functional outcome after six months of surgery. Rodriguez Merchan criteria contain different variables: the range of movement at shoulder and elbow joint, pain, and disability. All the data was recorded on designated Performa and entered and analyzed by SPSS version 20 .

\section{RESULTS}

Two hundred twenty-five patients of both sexes were included in the study, 146 (64.9\%) were male, and 79 (35.1\%) were female. The patients' mean age in the study was $38.06 \pm 11.51$, with a minimum range of 19 and a maximum age range of $67.137(60.9 \%)$ of cases sustained fracture shaft of the humerus as a result of a road traffic accident while $55(24.4 \%)$ and $33(14.7 \%)$ of cases were as a result of fall and assault, respectively. The right side was involved in $138(61.3 \%)$ cases, whereas the left side was $87(38.7 \%)$ cases. Fractures were classified according to $\mathrm{AO}$ classification, and according to $\mathrm{AO}$ classification, $102(45.3 \%)$ were of type $12 A 3$, while $57(25.3 \%)$, $46(20.4 \%)$, and $20(8.9 \%)$ were of type $12 \mathrm{~A} 2$, $12 \mathrm{~A} 1$, and $12 \mathrm{~B} 2$ respectively. The mean operative time was $54.29 \pm 7.0$ minutes. The mean union time of fracture in our study was $11.76 \pm 2.72$ weeks. The functional outcome was assessed using Rodriguez Merchan criteria. The excellent functional outcome was achieved in 165(73.3\%) cases and good functional outcome in 58 (25.8\%) cases. The fair outcome was achieved in $2(0.9 \%)$ of cases, as shown in Table-I. Stratification of data with gender and functional outcome out of 146 male patients' excellent outcomes was achieved in 107 cases, whereas good and fair outcomes in 37 and 2 cases respectively. While out of 79 female patients' excellent outcome was achieved in 58 and good outcome in 21 cases as shown in Table-II. Evaluation of data concerning functional outcome and type of fracture 46 patients was of AO type 12A1, out of which excellent outcome was achieved in 37 cases and good was achieved in 9 cases. 102 cases were of AO type 12A3 out of these excellent outcomes was achieved in 78 cases; good and fair outcomes were achieved in 23 and 1 cases, respectively. Out of the 57 cases of $A O$ type $12 \mathrm{~A} 2$, the excellent outcome was achieved in 37 cases, whereas good and fair outcome was achieved in 19 and 1 cases, respectively. Out of 20 cases of $\mathrm{AO}$ type 12B2, the excellent outcome was achieved in 13 cases and good in 7 cases, as shown in Table-III. The majority of the cases in the study were without complication. 217 patients showed no complication; the superficial infection was observed in $6(2.7 \%)$ cases, $2(0.9 \%)$ patients developed radial nerve injury as depicted in Table-IV. 


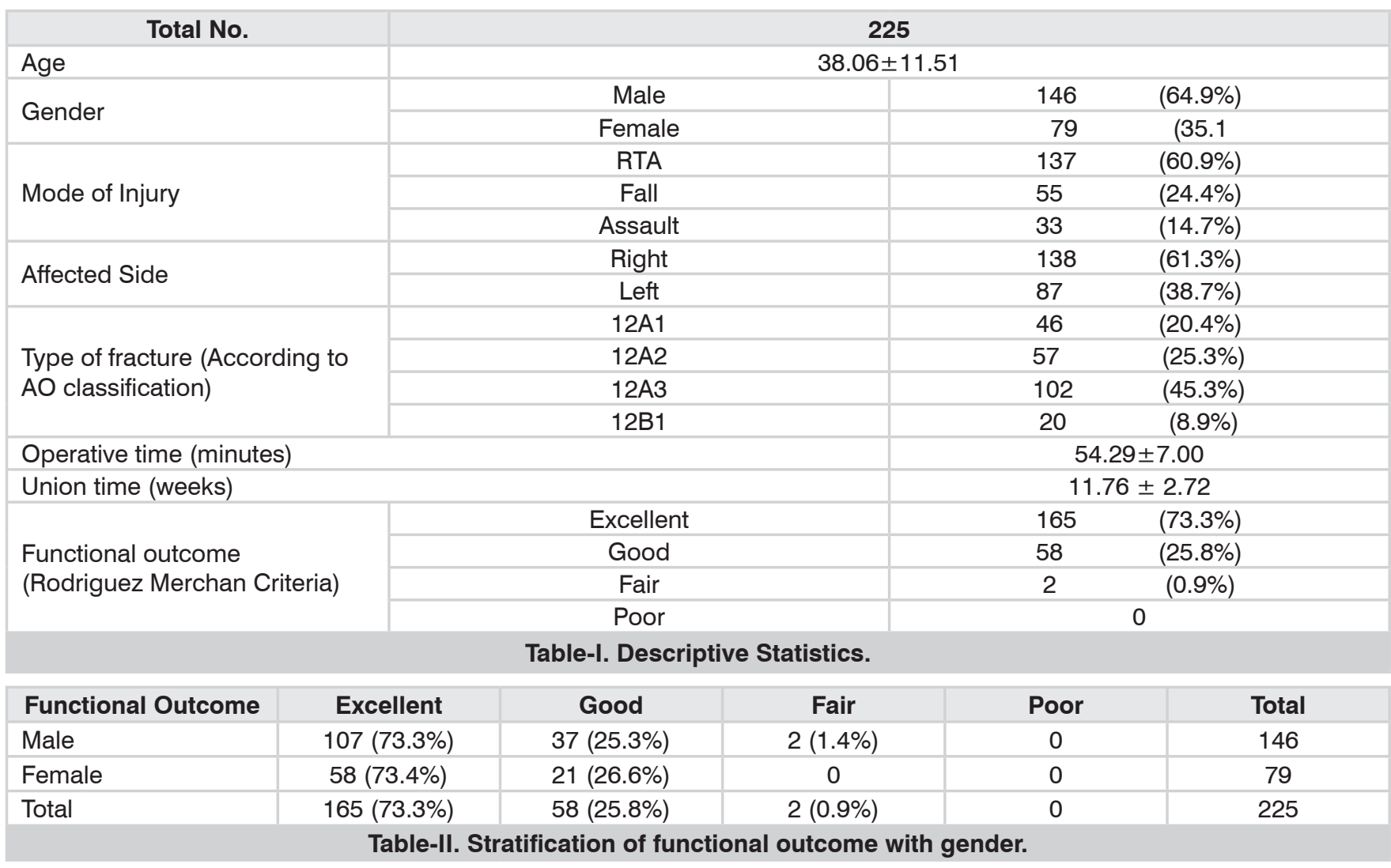

\begin{tabular}{|c|c|c|c|c|c|c|}
\hline \multicolumn{7}{|c|}{ Functional Outcome } \\
\hline \multirow{4}{*}{$\begin{array}{l}\text { Fracture type (according to } \\
\text { AO classification) }\end{array}$} & & Excellent & Good & Fair & Poor & Total \\
\hline & $12 \mathrm{~A} 1$ & 37 & 9 & 0 & 0 & 46 \\
\hline & $12 A 3$ & 78 & 23 & 1 & 0 & 102 \\
\hline & 12B2 & 13 & 7 & 1 & 0 & 20 \\
\hline Total & & 165 & 58 & 2 & 0 & 225 \\
\hline
\end{tabular}

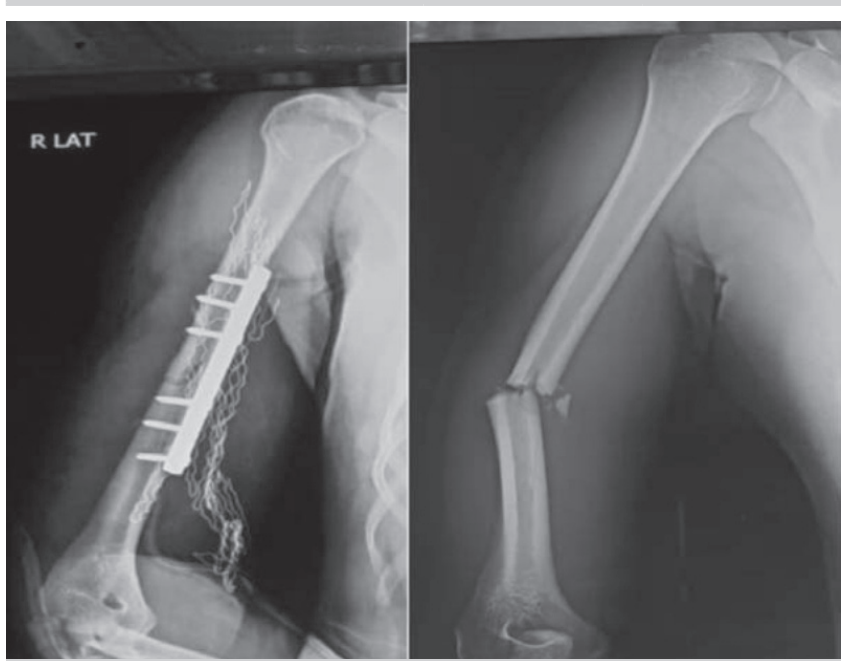

Figure-1. Pre-operative and postoperative radiograph of fracture shaft of humerus fixed by anteromedial plating.

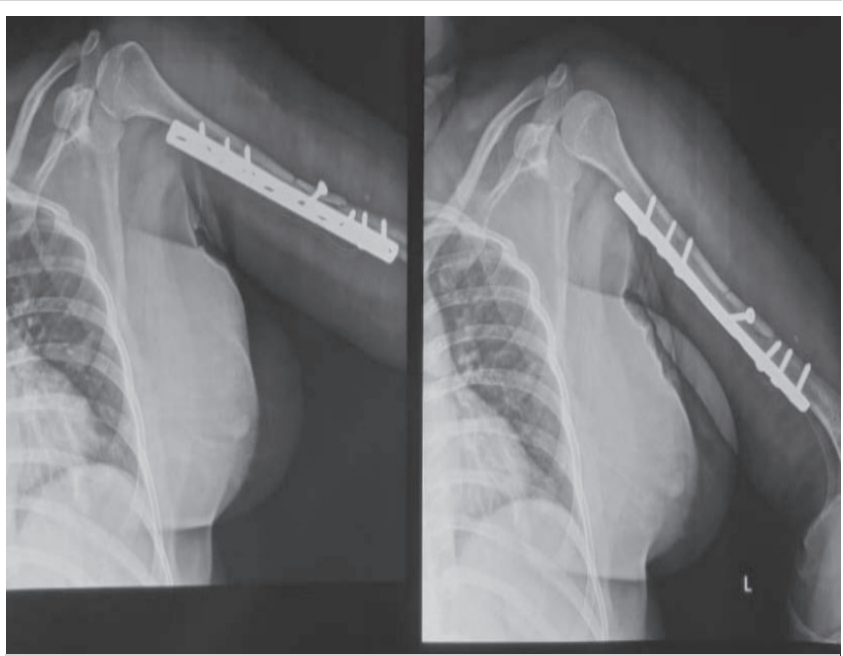

Figure-2. Postoperative picture of shaft of humerus fracture fixed by anteromedial plating. 


\begin{tabular}{|l|c|c|}
\hline & & Frequency \\
\hline no complication & 217 & 96.4 \\
\hline Superficial infection & 6 & 2.7 \\
\hline radial nerve injury & 2 & .9 \\
\hline Total & 225 & 100.0 \\
\hline
\end{tabular}

\section{DISCUSSION}

The union is not the only factor to achieve in treating the shaft of humerus fractures. Still, the other factors, such as good functional outcome and the preservation of the adjacent neurovascular structures, are of utmost importance. Plates and screws are treated as the ideal fixation device despite the recent advances in the implants. ${ }^{12}$ Humerus has been approached through different approaches, and each of them has its advantages and disadvantages. ${ }^{13}$ Concerning the shape and structure of humerus, the anterior and anteriormedial surface of humerus is flat, allowing accurate seating of plate compared to the lateral surface, which contains the attachment of deltoid muscle limits proper seating of plate over it. ${ }^{14}$ There has always been discussion regarding the treatment of shaft of humerus fracture, whether it should be managed by the MIPPO technique or open reduction and internal fixation. No difference in outcome with respect to the union has been observed in both except that the MIPPO technique has been associated with exposure to radiation. ${ }^{15}$ Plating, whether placed on the anterolateral surface or anteromedial surface, both have shown the same results. ${ }^{16}$ Anteromedial plating is relatively safe in terms of radial nerve injury, as Senthil ${ }^{17}$ showed no such complication in any of the cases. The union was achieved in all cases in the study for up to 12 weeks. Similarly, another study with the plating on the anteromedial surface showed that the union was achieved in all cases within 16 weeks. ${ }^{18}$ Dayez, in his study on medial plating of shaft of humerus, fractures excellent results in terms of no iatrogenic radial nerve injury, infection, or implant failures. ${ }^{19}$ These results in terms of no or lower percent of radial nerve injuries were reported by several different authors. $^{3,20}$

In our study, we found that males were more affected than females, and the right side was involved more than the left side. The majority of the fractures were of type 12A3. Union in our study was achieved in all cases, around 12 weeks ranging over a minimum of 8 weeks and a maximum of 18 weeks. Excellent and good outcome in our study was achieved in $99.1 \%$ of cases, and $0.9 \%$ of cases satisfactory outcome was achieved. No significant complications were observed in our study. The superficial infection was observed in 6 patients, but that didn't require any surgical intervention and were successfully managed by oral antibiotics. 2 patients developed signs of radial nerve injury that were most likely a result of increased pressure over the nerve while retraction by the assistant, that was managed by the wait and watch policy and both the cases resolved with full recovery by eight weeks.

\section{CONCLUSION}

Anteromedial plating of humerus shaft fractures provides stabile fixation, direct visualization, and plate placement on the bone surface protects the radial nerve from iatrogenic injury. We conclude that Anteromedial plating for the shaft of humerus fracture is a safe and easy procedure associated with little or no complications.

Copyright $@ 31$ Oct, 2020.

\section{REFERENCES}

1. Zhao JG, Wang J, Wang C, Kan SL. Intramedullary nail versus plate fixation for humeral shaft fractures: A systematic review of overlapping meta-analyses. Medicine (Baltimore). 2015 Mar; 94(11):e599. doi: 10.1097/MD.0000000000000599.

2. Egol AK, Koval JK, Zuckerman DJ. Handbook of Fractures, 4th edn. 2010; Wolters Kluver Lippincot Williams and Wilkin,New York.Page 203.

3. Kirin I, Jurisic D, Grebic D, Nadalin S. The advantages of humeral anteromedial plate osteosynthesis in the middle third shaft fractures. Middleast J Med. 2011; 123(3-4): 83-7.

4. Cole PA, Wijdicks CA. The operative treatment of diaphyseal humeral shaft fractures. Hand Clin 2007; 23:437-48, VI. 
5. Kurup, H.; Hossain, M.; Andrew, J.G. Dynamic compression plating versus locked intramedullary nailing for humeral shaft fractures in adults. Cochrane Database Syst. Rev. 2011. [CrossRef] [PubMed].

6. Riemer BL, Foglesong ME, Burke CJ 3rd, Butterfield SL. Complications of Seidel intramedullary nailing of narrow diameter humeral diaphyseal fractures. Orthopedics 1994; 17:19-29.

7. Stannard JP, Harris HW, McGwin G Jr., Volgas DA, Alonso JE. Intramedullary nailing of humeral shaft fractures with a locking flexible nail. J Bone Joint Surg Am 2003; 85-A: 2103-10.

8. Livani B, Belangero W, Medina G, Pimenta C, Zogiab $\mathrm{R}$, Mongon $\mathrm{M}$, et al. Anterior plating as a surgical alternative in the treatment of humeral shaft nonunion. Intl Orthopaedics (SICOT). 2010 Oct; 34(7):1025-31

9. Stuby FM, Höntzsch D. Humerus shaft fractures. Z Orthop Unfall. 2009 May-Jun; 147(3):375-86; quiz 38790. doi: 10.1055/s-0029-1185702.

10. Paris H, Tropiano P, Clouet D'Orval B, Chaudet $H$, Poitout DG. Fractures of shaft of humerus; systematic plate fixation. Anatomic and functional results in 156 cases and a review of litrature. Rev Chir Orthop Reparatrice Appar Mot. 2000 Jun; 86(4):346-59.

11. Akan B, Armangil M, Basarir K, Acar H, Bilgin S, Demirtas M. Clinical evaluation of an anteromedial approach for plate fixation of the proximal humeral shaft. Eur $\mathrm{J}$ Orthop Surg Traumatol 2012; 22:289-93. doi: 10.1007/ s00590-011-0843-5.

12. Zheng J, Jun-Lin Z, Xiao-Hong W, Lei Shan, Yang Liu. Biomechanical study of fixation strength of anteromedial plating for humeral shaft fractures, Chin. M. J 2016; 15 Vol. 129:1850-5.
13. Mills WJ, Hanel DP, Smith DG. Lateral approach to the humeral shaft: An alternative approach for fracture treatment. J Orth op Trauma 1996; 10:81-6.

14. Oh, C.W., Byun, Y.S., Oh, J.K., Kim, J.J., Jeon, I.H., Lee, J.H. and Park, K.H. Plating of humeral shaft fractures: Comparison of standard conventional plating versus minimally invasive plating. Orthopaedics \& Traumatology: Surgery \& Research, 2012:98; 54-60. http://dx.doi.org/10.1016/j.otsr.2011.09.016.

15. Hun Lu, Junwei $X u$, Baisheng Fu, Jinlei D, Yongliang $Y$, Guodong Wang, Maoyuan X, Qinghu L, Tong-Chuan H, Fu Wang, Dong Sheng Z.: Evaluation of the surgical treatment of humeral shaft fractures and comparison between surgical fixation methods Medial approach to treat humeral mid-shaft fractures: A retrospective study. J. Orthop. Surg. Res 2016; 11: 32.

16. Senthil L, Jambu N, Chittranjan BS. Anteromedial plating of humerus - An easier and effective approach. Open J Orthop 2015; 5:305-10.

17. Kumar B.S, SoraganviP, SatyarupD. Treatment of middle third humeral shaft fractures with anteromedial plate osteosynthesis through an anterolateral approachMalays Orthop. J 2016; Mar., 10 (1): 38-43.

18. Dayez J. Internal screwed plate for recent fractures of the humeral diaphysis in adults. Rev Chir Orthop Reparatrice Appar Mot 1999; 85:238-44.

19. Rommens PM, Endrizzi DP, Blum J, White RR. Humerus shaft. In: Rudi TP, Murphy WM, Eds. AA AO principles of fracture management. Stuttgart and New York: Thieme 2000; pp. 291-305.

20. Lu S, Wu J, Xu S, Fu B, Dong J, Yang Y, et al. Medial approach to treat humeral mid-shaft fractures: $A$ retrospective study. J Orthop Surg Res 2016; 11:32.

\begin{tabular}{|c|c|c|c|}
\hline \multicolumn{4}{|c|}{ AUTHORSHIP AND CONTRIBUTION DECLARATION } \\
\hline Sr. \# & Author(s) Full Name & Contribution to the paper & Author(s) Signature \\
\hline 1 & Masroor Ahmed & $\begin{array}{l}\text { Concept design, collection and assembly of } \\
\text { data, drafting of article, final approval and }\end{array}$ & poss \\
\hline 2 & Muhammad Bux & $\begin{array}{l}\text { Collection and assembly of data, Drafting of } \\
\text { article. }\end{array}$ & $M B$ \\
\hline 3 & Naveed Ahmed & $\begin{array}{l}\text { Collection and assembly of data, Critical } \\
\text { reivsion of the article for intellectual content. }\end{array}$ & $N A$ \\
\hline 4 & Mukesh Kumar & $\begin{array}{l}\text { Critical revision of the article for intellectual } \\
\text { content. }\end{array}$ & Makfestit \\
\hline 5 & M. Ishtiyaque & Analysis and interpretation of data. & $M / Q$. \\
\hline 6 & Ghulam Hussain & Analysis and interpretation of data. & Hrume \\
\hline
\end{tabular}

